\title{
Old rocks drown dry Moon theory
}

\section{Samples collected during Apollo missions suggest a wet interior, raising questions about lunar origins.}

\section{Larry Taylor always said he'd eat his shorts if water was ever found on the Moon. He never expected his own research to bring that pledge back to haunt him. \\ The petrologist, based at the University of Tennessee in Knoxville, was just 32 years old at the first Lunar and Planetary Science Confer- ence in 1970, where his colleagues described their analyses of Moon rocks collected the pre- vious year during the Apollo 11 mission. Taylor saw only pure metallic iron in the samples - a sign that there wasn't any water around to rust the iron. This and other results that year led to the party line: the Moon is, and always was, bone dry.}

Forty years on, at the same annual conference near Houston, Texas, Taylor and his colleagues announced that they have been wrong all along. At the meeting last week, three groups presented evidence that certain crystals in the volcanic rocks collected by Apollo astronauts contain as much as several thousand parts per million of water.

These findings go much deeper than the glimpses of frozen water on the Moon's surface - discoveries that were made recently by India's Chandrayaan-1 and NASA's Lunar Reconnaissance Orbiter spacecraft (see Nature doi:10.1038/ news.2009.931; 2009). The new studies of the Apollo samples provide hints of what lurks within the Moon.

The results suggest that the lunar interior has always held some water - challenging theorists to change their thinking about how the Moon

The findings go deeper than the glimpses of frozen water on the Moon's surface; the Apollo samples provide hints of what lurks within the Moon. formed during a fiery impact, and how the once-molten body cooled. The work also hints that comets have played a more important part in delivering water to the Moon than researchers had previously thought.

"This is revolutionary," says Linda ElkinsTanton, a lunar scientist at the Massachusetts Institute of Technology in Cambridge. As for Taylor, the one-time water sceptic has eaten his words - and more. In January, colleagues gave him a chocolate cake, iced white with pink polka dots to represent his boxer shorts.
The first clues to a wet lunar interior were published in 2008, says Taylor, after researchers found traces of water buried inside beads of volcanic glass found in Apollo samples (A. E. Saal et al. Nature 454, 192-195; 2008). It took advances in ion mass spectrometers to detect such tiny amounts of water. It also required people willing to challenge 40 years of conventional wisdom and endure the chuckles of disbelieving colleagues.

Although the volcanic beads offered evidence for inner water, those rocks also had limitations. The beads formed in violent, 'fire-fountain' eruptions that significantly altered their chemistry, making them uncertain proxies for rocks inside the Moon.

The new detections of water came from a different source - tiny apatite crystals found within dark basalt from the Moon's maria, or 'seas'. The crystals, which took shape within the vast fields of flowing lava that once filled the maria, contain much higher amounts of water than the glass beads.

Because the basalt came from quieter eruptions than the dramatic fire fountains that formed the glass, Taylor says, the chemistry of these rocks can more easily be used to calculate the water content of the original magma body from which they came, deep in the Moon's mantle.

The three groups at the meeting reached different conclusions about the past water content of the Moon, but all three suggest that the lunar interior could have contained tens of thousands of times more water than previously thought, although still orders of magnitude less than Earth.

A Moon with so much moisture would have been a more active place. Water lowers the melting point of mantle rock and makes it easier for magma to form. It even allows for the possibility of convection of rock inside the Moon, something long discounted. This would have helped the Moon to cool more quickly than researchers previously thought, and could explain some puzzling aspects of lunar geology.

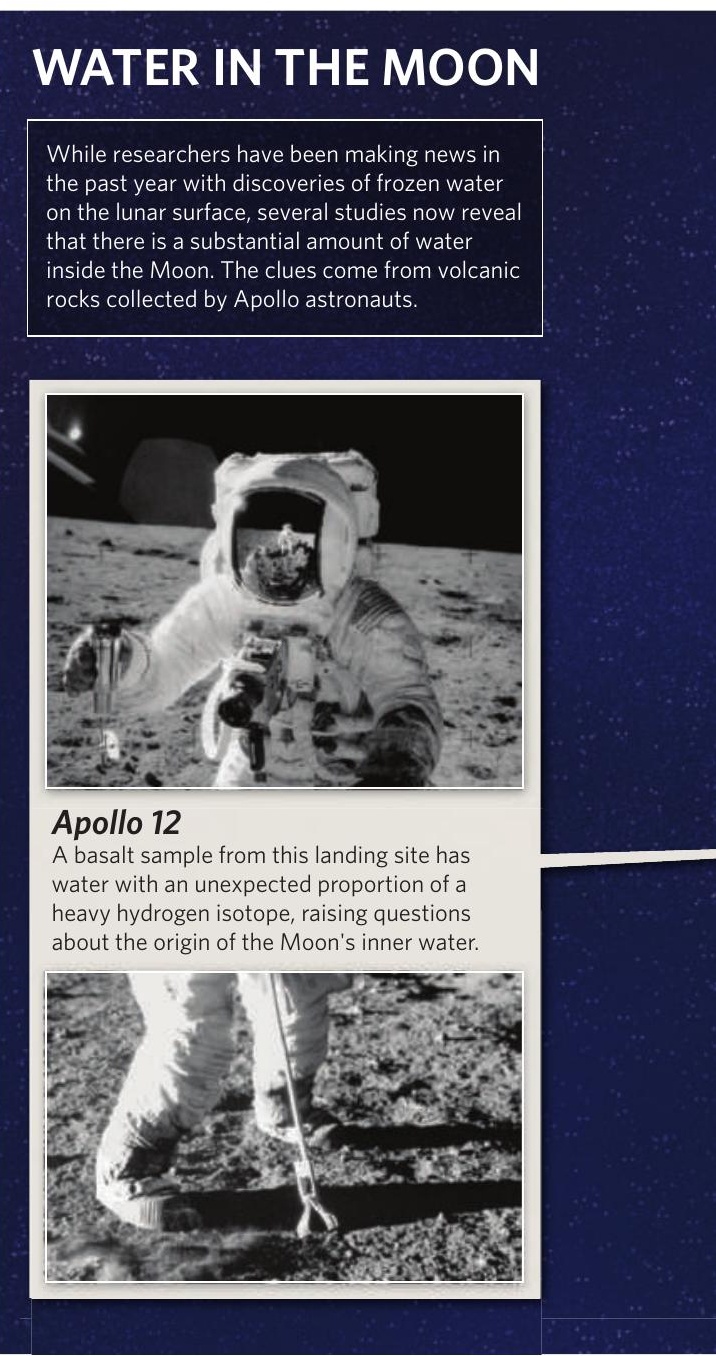

One of the groups went further and discovered a clue to the origins of the water. James Greenwood of Wesleyan University in Middletown Connecticut, working with Taylor, found that Moon water has a much higher proportion of deuterium, or heavy hydrogen, than does water on Earth. The ratio found for the Moon resembles that of comets.

\section{A weighty problem}

This ratio came as a surprise. The Moon is thought to have formed when a Mars-sized body hit Earth soon after its formation, melting much of the planet and flinging up molten rock that eventually coalesced and hardened to form a satellite. That picture suggests that Earth and the Moon should have started with similar ratios of heavy water.

But the markedly heavier mix of water in the lunar samples has forced researchers to consider alternative explanations. One idea, Taylor says, is that a bevy of comets struck the Moon soon after the giant impact responsible 

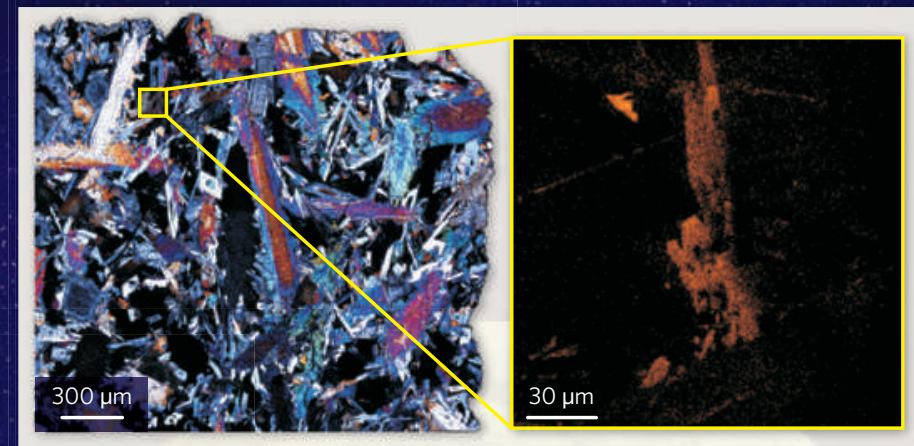

Apollo 15

A grain of the mineral apatite

shows off

rainbow hues

under a

microscope.

Locked inside are

hydroxyl ions

(orange, inset)

revealing the

presence of

water.

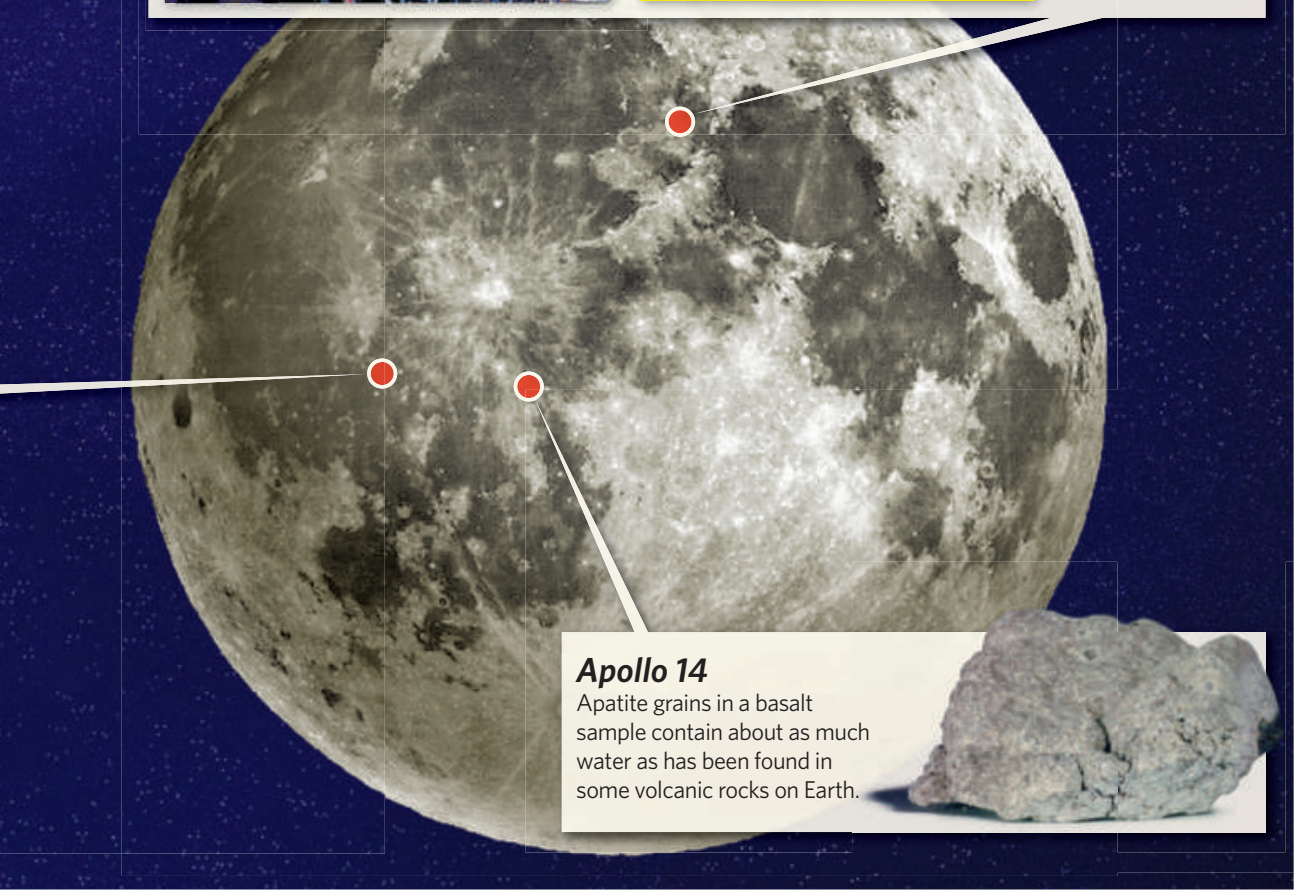

for its formation, and that the heavy comet water mixed into the Moon's magma ocean. The comets would have struck Earth too, but because the young planet had a significantly larger supply of water, the heavy water deposited on Earth was greatly diluted.

Alternatively, perhaps the heat of the impact evaporated the lighter water from the Moon, leaving it enriched in heavier water. Or maybe the impactor itself contained large amounts of heavy water.

According to Elkins-Tanton, "this may all lead to a reconsideration of the giant-impactor theory," especially in how it relates to the origin of lunar water.

But not yet. The heavy-water results could reflect nothing more than a specific spot of enrichment - the impact site of an ancient comet, for example. And some researchers aren't convinced that the Moon is a wet as the new results suggest.

Chip Shearer at the University of New Mexico in Albuquerque has been analysing chlorine in volcanic rocks, which can provide some information about ancient water because of the way chlorine would have bound to it to form other compounds. $\mathrm{He}$ says that the estimated water concentrations reported last week are at the upper limit of the range allowed by his chlorine results.

Sorting out the debate will require new samples. To Clive Neal at the University of Notre Dame in Indiana and chair of a NASA lunar advisory group, that means returning to the Moon. But before then, researchers will be revisiting the rocks collected by Apollo astronauts.

At the meeting last week, Taylor drew an index card out of his wallet that contained the five-digit codes for three more samples he was going to retrieve from the vaults at the Johnson Space Center, on the other side of Houston from the conference. He has made the trip many times before. "Being an old fart," he says, "I know the ropes."

Eric Hand

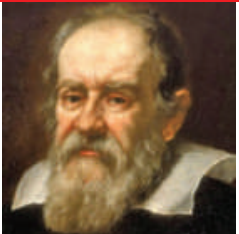

GALILEO BACKED COPERNICUS DESPITE DATA

Early telescopes suggested that Earth stood still.

go.nature.com/OV49Sv

\section{Biology thinks big to stay cuts}

Biologists with grandiose research proposals often turn to the risk-tolerant Human Frontier Science Program (HFSP) to get themselves started. However, the world's only intercontinental research funding agency is now working hard to convince its members -13 individual nations plus representation from the European Union - that frontier research is a wise investment in tough economic times. The 20-year-old HFSP distributes about US\$60 million a year to support research into complex biological systems. Last week, the programme's secretary-general, geneticist Ernst-Ludwig Winnacker, met with an elite group of about two dozen scientists to discuss where the frontiers of biology might lie.

Participants agreed that genetic technologies will continue to be central to frontier biology; that fields such as microscopy will continue to drive it; and that new developments in chemistry will feed it. Tom Henzinger of the Institute of Science and Technology in Vienna also convinced participants that pure mathematics could become an increasingly useful tool in understanding biological processes.

"We remain open to any approach — the three sole criteria remain excellence, risk and biology," says Winnacker, who has previously served as secretary-general of the European Research Council and president of the German research agency the DFG.

The general messages from the brainstorming session will feed into the organization's first formal strategy report, which will be crucial when the HFSP's members meet in May. Winnacker is already bracing himself for trouble: Japan, which normally contributes around half of the budget, has this year cut its contribution by $5 \%$, and the global financial crisis is squeezing all members. Winnacker hopes that the report will help to secure continued funding for this unique programme, whose unbureaucratic support of big ideas is popular with scientists. "It is a paradox that science is international, but funding is regional or national," Winnacker notes. "The HFSP is the only agency with none of the political borders that make joint funding so complicated." 